\title{
Ultrasonography compared to magnetic resonance imaging in thyroid-associated Graves' ophthalmopathy
}

\author{
Comparação de ultrassonografia à ressonância magnética \\ nuclear na oftalmopatia de Graves associada à tiroide
}

Ana R. Vlainich', João H. Romaldini², Ana B. Pedro², Chady S. Farah ${ }^{2}$, Cicero A. Sinisgalli Jr. ${ }^{3}$

${ }^{1}$ Ophthalmology, Services at Hospital Servidor Publico Estadual de Sao Paulo (IAMSPE) São Paulo, SP, Brazil

${ }^{2}$ Endocrinology, IAMSPE, São Paulo, SP, Brazil ${ }^{3}$ Radiology, IAMSPE, São Paulo, SP, Brazil
Correspondence to Ana R. Vlainich Av. Paes de Barros, 1899, ap. 52 03115001 - São Paulo, SP, Brazil anavlainich@uol.com.br

Received on Feb/24/2010 Accepted on Mar/9/2011

\section{ABSTRACT}

Objective: To compare ultrasonography (US) to magnetic resonance imaging (MRI) and the clinical activity score (CAS) in Graves' ophthalmopathy. Subjects and methods: Nineteen patients underwent extraocular muscle thickness measurements by US and MRI, reflectivity by US and signal-intensity ratio by MRI. There were also twelve US control subjects. Results: US median thicknesses were greater than in controls. Correlation was found between US and MRI in the median thickness of the left eye rectus medial muscle as well as between signal-intensity ratio (SIR) and thickness by US. An inverse correlation was found between reflectivity and SIR in the inferior and lateral rectus. On associating the tests for detecting activity the best results were obtained with CAS plus MRI (sensitivity $75 \%$ ), and US and MRI (positive predictive value $77 \%$ and specificity $80 \%$ ). Conclusion: CAS and US results showed poor correlation with MRI results suggesting that they cannot replace each other but when combined these methods can improve the evaluation of thyroid-associated ophthalmopathy. Arq Bras Endocrinol Metab. 2011;55(3):184-8

\section{Keywords}

Graves' disease; thyroid-associated ophthalmopathy; orbital ultrasonography; magnetic resonance imaging

\section{RESUMO}

Objetivo: Comparar a ultrassonografia (US) à ressonância magnética nuclear (RMN) e o índice de atividade clínica (IAC) na oftalmopatia de Graves. Sujeitos e métodos: Dezenove pacientes submetidos à medida da espessura dos músculos extraoculares por US e RMN, refletividade ao US e razão da intensidade de sinal (RIS) à RMN. Grupo controle para US de 12 indivíduos. Resultados: Espessura mediana ao US foi maior que dos controles. Houve correlação entre US e RMN na espessura mediana dos músculos retos mediais dos olhos esquerdos e entre a RIS e a espessura ao US e correlação inversa entre refletividade e SIR nos retos inferior e lateral. Detectando atividade, os melhores resultados foram associando IAC e RMN (sensitividade de $75 \%$ ) e US e RMN (valor preditivo positivo de $77 \%$ e especificidade de $80 \%$ ). Conclusão: Resultados do IAC e US mostraram pouca correlação com a RMN, sugerindo que não podem ser substituídos, mas, quando combinados, esses métodos podem melhorar a avaliação da oftalmopatia associada à tiroide. Arq Bras Endocrinol Metab. 2011;55(3):184-8

\section{Descritores}

Doença de Graves; oftalmopatia associada à tiroide; ultrassonografia orbitária; ressonância magnética nuclear

\section{INTRODUCTION}

Thyroid-associated ophthalmopathy (TAO) is an autoimmune disorder of the orbit associated with Graves' disease (GD) which presents signs and symp- toms in $50 \%$ of the cases (1-3), even though activity is clinically detected in few cases (2-4). The natural course of the disease shows an initial active phase followed by an inactive phase $(4,5)$. Abnormalities of the 
clinical activity are associated with lymphocytic infiltration and edema, whereas inactivity is associated with fibrosis $(6,7)$, both producing proptosis $(2,6,7)$. Treatments are more effective in the active phase, thus its determination is essential $(1,4,7,8)$ but management fails in $50 \%$ of the cases probably due to the difficulty $(4,6,7)$ in identifying the disease phase $(8)$. The clinical activity score (CAS) is not enough to help diagnosis for this reason different imaging techniques that enable visualization of the orbit contents and evaluation of extraocular muscles (EOM) have been tested (9-11). US enables differential diagnosis in proptosis and seems to reveal the existing inflammation (12-17). Computed tomography scan (CT) shows muscle thickness, diagnoses compressive optical neuropathy and defines the degree of proptosis but does not detect activity $(1,10,18)$. Therefore, MRI seems to be the most suitable method because it reaches the retraction of the upper eyelid (18), the activity of the muscles and the increase in orbital fat $(1,4,19-23)$. To present, few studies have compared US with MRI in assessing TAO $(20,22,24)$. In this study we compared TAO orbits within different activity levels using US, MRI, and CAS.

\section{SUBJECTS AND METHODS}

Nineteen patients were examined ( 15 women - 4 men) with uni- or binocular TAO, mean age and standard deviation were $39.3 \pm 13.2$ years (range $16-59$ years), there were $6(31 \%)$ smokers and the duration of the disease was $21.7 \pm 16.4$ months $(3-60$ months). CAS was assessed by the physicians (ABP and CSF) and ranged from 0 to 7 , any score higher than 3 was considered to be active TAO disease. GD was diagnosed based on characteristic signals and symptoms plus diffuse goiter, confirmed by suppressed serum TSH, elevated free total T4 levels, thyroid peroxidase (TPO$\mathrm{Ab})$, thyroglobulin $(\mathrm{TgAb})$ and thyroid receptor antibodies (TRAb), and increase in thyroid radioactive iodine uptake. Hypothyroidism was diagnosed by elevated serum TSH and low free T4 levels. Proptosis was measured by Hertel exophthalmometer. The US control group consisted of 12 age- and gender-matched subjects with normal clinical, laboratorial data, and ophthalmologic examinations. All patients underwent US and MRI, done no later than three weeks apart, with the control group submitted only to the US. Exclusion criteria were previous ocular surgery, problems in performing MRI (claustrophobia), or anything that could hinder US performance (e.g. high myopia). The study was approved by the Medical Ethics Committee and written informed consent terms were obtained from all subjects.

Serum free T4 and TSH concentrations were measured by fluoroimmunoassay (Delphia; Pharmacia), normal ranges were 0.8 to $2.0 \mathrm{ng} / \mathrm{mL}$ and 0.3 to 4.0 $\mathrm{mU} / \mathrm{L}$, respectively. TRAb was determined by TSH-receptor antibody kit supplied by RSR Ltd. (Cardiff, Wales, UK) and was expressed as the percentage of inhibition of 125-I-labelled bovine TSH binding to the TSH receptor, normal values were considered less than $11 \mathrm{IU} / \mathrm{L}$. To determine TPOAb and TgAb, direct RIA system supplied by RSR Ltd was used and normal range was less than $1.0 \mathrm{IU} / \mathrm{L}$.

The EOM assessed were the inferior rectus (IR), rectus medial (RM), rectus lateral ( $\mathrm{RL}$ ) and rectus superior (RS). The US was performed by the same examiner (ARV) with A\&B USA Humphrey Instruments Inc. $10 \mathrm{Mh}$ model 837 , in primary eye position, low gain, logarithmic curve, muscle diagonal section $(2,12,25,26)$. Thickness $(7,16)$ and reflectivity were assessed using the maximum thickness inside the muscle capsules $(12,16,17)$. Using printed images, the average of the height of all peaks from baseline to the top, between the external borders of the muscles, was calculated as a percentage of the sclerotic peak $(12,16,17)$.

Orbital MRIs were analyzed by the same radiologist using a 1.5 Tesla MR unit head coil (General Electric Co., Milwaukee, USA). The pulse sequences were T1-weighted, spin-echo, axial (TR 366, TE12, $3 \mathrm{~mm} \mathrm{sec-}$ tion thickness (ST)) and coronal plane (TR 500, TE $17,4 \mathrm{~mm} \mathrm{ST}$ ) used for muscle thickness measurements, and T2- weighted, fast-spin-echo, axial (TR 3000, TE 103, $3 \mathrm{~mm} \mathrm{ST}$ ) and coronal plane (TR 300; TE98.7, $4 \mathrm{~mm} \mathrm{ST}$ ). Coronal plane was used to examine RS and IR and the axial plane to examine RM, RL, and cerebral substantia alba (SA). Furthermore, the T2 signal intensity of the muscles was compared to the SA signal and expressed as a signal-intensity ratio (SIR) in order to reduce individual differences and to compensate for the slight variation in machine sensitivity when used on subsequent occasions. This ratio also eliminates the need to submit the control group to MRI $(10,21,24,27-29)$. An increase in SIR might indicate activity due to edema presence $(11,18,27,28,30)$.

Statistical analysis was performed using the tests: GB-STAT software package and Kolmogorov-Smirnov, Mann-Whitney U, Student's t; the Wilcoxon Rank- 
-Sum, Fischer's Exact, ANOVA and the Spearman coefficient. Statistical significance was set at $5 \%(\mathrm{P}<0.05)$.

\section{RESULTS}

The mean CAS value of TAO patients was $2.4 \pm 1.3$ (range 1 to 6 ) and $63.1 \%$ of the patients were diagnosed as in active phase. However, using MRI 15 (78.9\%) patients showed activity (at least 1 muscle with SIR higher than 1.5$)(21)$, while only 8 (42.1\%) showed activity by US (reflectivity smaller than $40 \%$ in at least one muscle). Proptosis (above $20 \mathrm{~mm}$ ) was observed in 13 patients $(68.4 \%)$ with a mean of $24.2 \pm 2.2 \mathrm{~mm}(22-30 \mathrm{~mm})$ that was significantly higher $(\mathrm{P}>0.001)$ than in the control group $(14.7 \pm 2.1 \mathrm{~mm} ; 12-18 \mathrm{~mm})$. Figure 1 shows US image of one patient and figure 2 MRI-T2 in coronal section. Based on US measurements, there was significant difference using ANOVA analysis ( $\mathrm{P}=$ 0.0006) of IR mean thickness compared to controls (Figure 3), whereas no differences were found in their respective reflectivity. Correlation was found between median thicknesses RM in the left eye as measured by US and by MRI $(\mathrm{r}=0.51 ; \mathrm{P}<0.02)$ (Figure 4$)$, as well as between SIR and thickness by US $(r=0.35$; $\mathrm{P}<0.004$ ) (Figure 5). However, there was no correlation between CAS or proptosis with any muscle value measured by US, MRI or smoking. Furthermore, an inverse correlation was noted between reflectivity and SIR in IR $(r=-0.63 ; \mathrm{P}<0.003)$ and $\mathrm{RL}(\mathrm{r}=-0.39 ; \mathrm{P}<$ 0.01 ) (Figure 6). An interesting analysis was obtained by associating the tests for detecting activity and the best results were achieved for CAS plus MRI reaching a sensitivity of $75 \%$, and US and MRI with positive predictive value of $77 \%$ and specificity of $80 \%$ (Table 1 ).

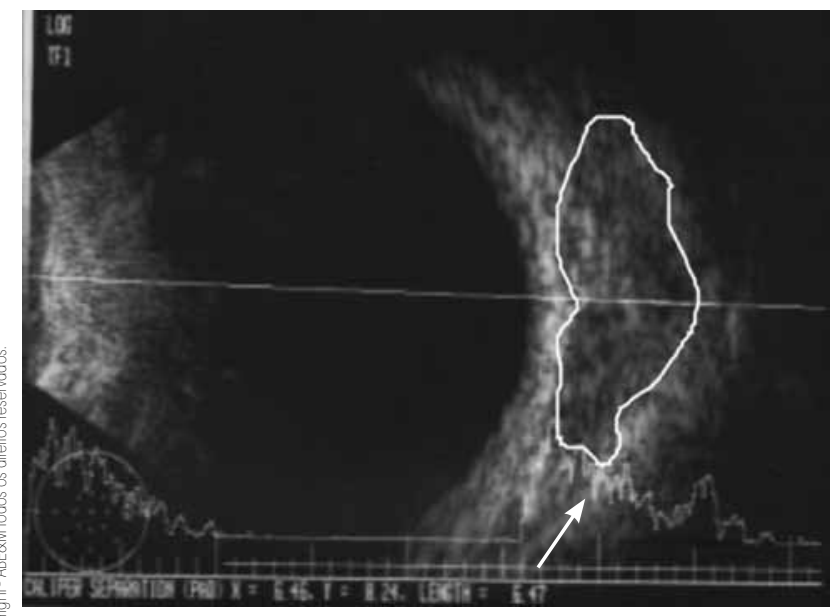

Figure 1. Shows US B-mode image of right rectus muscle in a TAO patient.

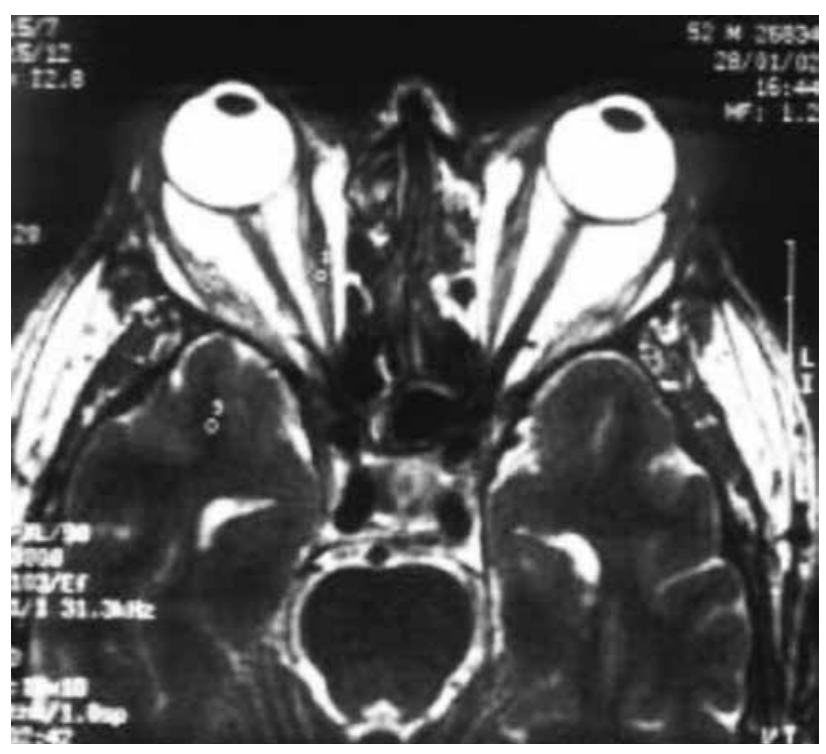

Figure 2. Shows axial MRI image at $\mathrm{T} 2$ to evaluate lateral and medial rectus besides substantia alba.

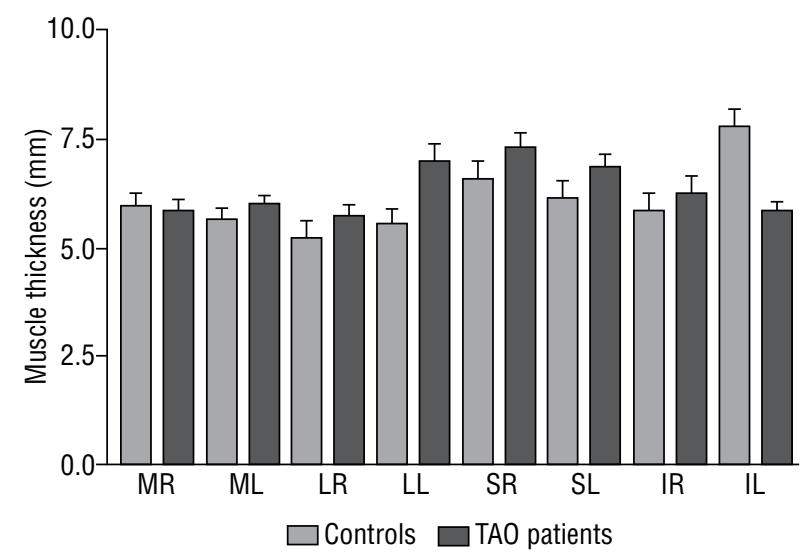

MR: right medial rectus, ML: left medial rectus, LR: right lateral rectus, LL: left lateral rectus, SR: right superior rectus, SL: left superior rectus, IR: right inferior rectus, IL: left inferior rectus.

Figure 3. Significant Anova $(P=0.0006)$ of rectus muscle thickness measured by ultrasound in TAO patients and controls.

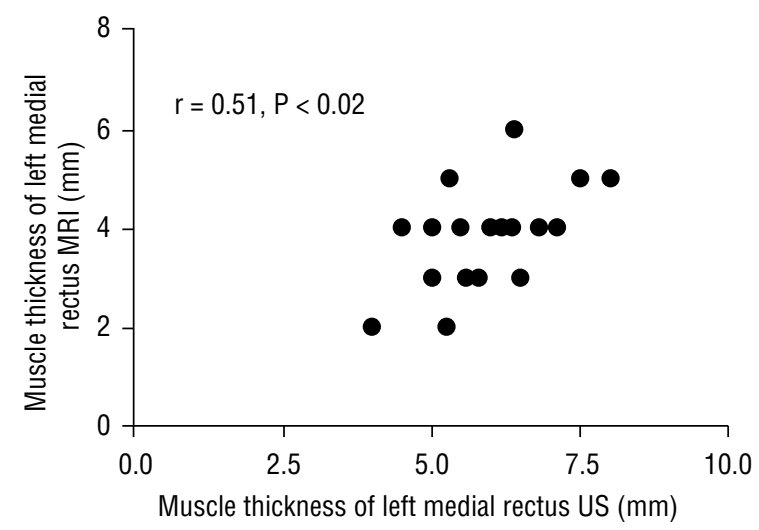

Figure 4. Spearman correlation between medial rectus in the left eye by ultrasound and magnetic resonance imaging in $\mathrm{mm}$. 


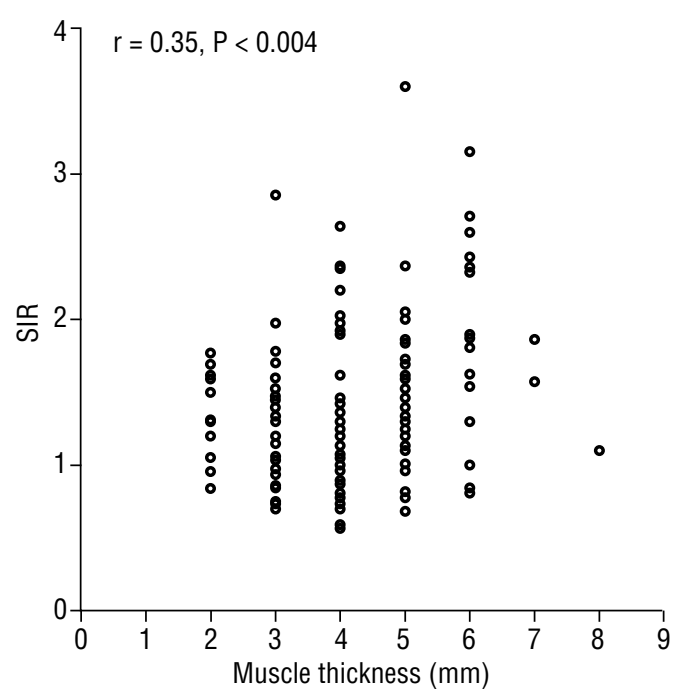

Figure 5. Spearman correlation between extraocular muscles signalintensity ratio (SIR) by MRI and thickness measured by US.

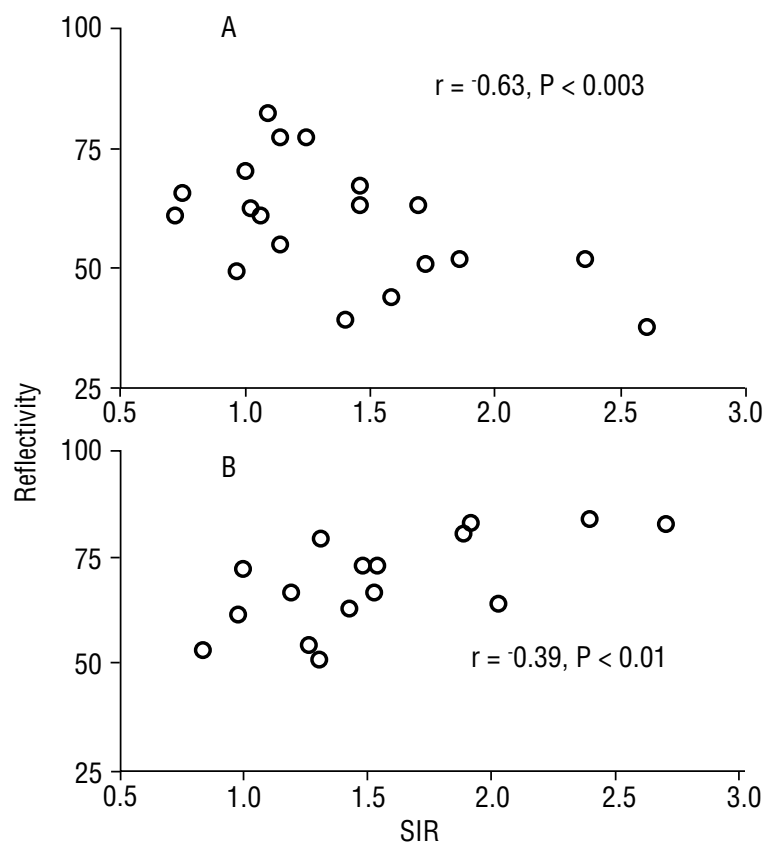

Figure 6. Spearman inverse correlation found between US reflectivity and MRI SIR of the inferior (A) and lateral (B) rectus muscles.

Table 1. Calculating predictive positive value PpV, predictive negative value $\mathrm{PnV}$, sensitivity and specificity expressed in \% when associating the tests for detecting TAO activity. CAS considered $>3$, reflectivity considered $>40 \%$ and SIR considered $>1.5$

\begin{tabular}{lcccc}
\hline & PpV & PnV & Sensitivity & Specificity \\
\hline CAS plus reflexivity & 44 & 58 & 25 & 77 \\
CAS plus SIR & 42 & 60 & 75 & 27 \\
SIR plus reflexivity & 77 & 27 & 25 & 80 \\
\hline
\end{tabular}

\section{DISCUSSION}

In the present study, no relationship was observed between GD status (hyperthyroidism, euthyroidism, or hypothyroidism) and CAS of patients with TAO, confirming data from other studies $(3,6,7)$. Additionally, some authors found that ultrasound results are more sensitive than clinical exam $(16,17)$. Prummel and cols. (12) showed that EOM in patients with TAO and active inflammation presented different reflectivity, deducing that US reflectivity is a reliable method to determine TAO disease activity.

Several explanations can be given for the poor correlation between US and MRI in EOM thickness measurement: external eye muscles are oval-shaped and US examinations are not made at a perfect perpendicular angle (14); low US accuracy could be due to the presence of some artifacts or fibrosis often found in TAO EOM, which makes muscle delimitation very difficult $(10,14,24)$, and the fact that MRI seems to be more accurate to visualize the back portion of the orbit (24).

Several methods have been tested to determine disease activity $(1,25)$ and better response to immunosuppressive treatment $(10)$. CAS helps predict response to treatment $(4,8,16,27)$ but works better if combined with US reflectivity $(8-10,16,26,31)$. On the other hand, the orbital octreoctide scan method $(10,30)$ and MRI are more expensive and not as readily available in healthcare facilities; furthermore, as stated by Hoh and cols. (21), MRI may fail to differentiate inactive fatty degeneration.

Similar to other studies $(8,32,33)$, no correlation was found between CAS and reflectivity or SIR, perhaps because CAS has wide a variation among observers $(1,4)$ or because the great majority of imaging methods assesses only the EOM and not orbital fat inflammation $(4,8)$. We noted that combining the US and MRI resulted in significant increase in the positive predictive value and in specificity. However, US does not provide the comprehensive amount of information on the EOM that is available with the use of MRI. SIR determination is considered to reflect free water content, thus an increase usually indicates edematous changes during the active phase of TAO $(23,29)$.

Although our data is limited by the absence of highly active orbits, CAS and US results were somehow poorly correlated to MRI results what suggests that they cannot replace each other but from a clinical point of view when used in combination these methods can 
help in the evaluation of this multifaceted and challenging disease.

Disclosure: no potential conflict of interest relevant to this article was reported.

\section{REFERENCES}

1. Bartalena L, Tanda ML. Graves' ophthalmopathy. N Engl J Med. 2009;360:944-1001.

2. Villadolid MC, Yokoyama N, Izumi M, NishikawaT, Kimura H, Ashizawa $\mathrm{K}$, et al. Untreated Graves' disease patients without clinical ophthalmopathy demonstrate a high frequency of extraocular muscle enlargement by magnetic resonance. J Clin Endocrinol Metab. 1995;80:2830-3.

3. Asman P. Ophthalmological evaluation in thyroid-associated ophthalmopathy. Acta Ophthalmol Scand. 2003;81:437-48.

4. Bartalena L, Pinchera A, Marcocci C. Management of Graves' ophthalmopathy: reality and perspectives. Endocr Rev. 2000;21:168-99.

5. Franzco DS, Cehn C, King G. Late reactivation of thyroid orbitopathy. Clin Experiment Ophthalmol. 2004;32:46-50.

6. Wiersinga WM, Prummel MF. An evidence-based approach to the treatment of Graves' ophthalmopathy. Endocrinol Metabol Clin North Am. 2000;29:297-319.

7. Wiersinga WM. Management of Graves' ophthalmopathy. Nature Endocrinol Metab. 2007;3:396-404.

8. Mourits M, Koornneef I, Wiersinga WM, Prummel MF, Berghout A, Van der Gaag R. Clinical criteria for the assessment of disease activity in Graves' ophthalmopathy: a novel approach. Br J Ophthalmol. 1989;73:639-44.

9. Prummel MF. Graves' ophthalmopathy: diagnosis and management. Eur J Nucl Med. 2000;27:373-6.

10. Kahaly GI. Imaging in thyroid-associated orbitopathy. Eur J Endocrinol. 2001;145:107-18.

11. Bartley GB, Gorman CA. Diagnostic criteria for Graves' ophthalmopathy. Am J Ophthalmol. 1995;119:792-5.

12. Prummel MF, Suschulten MSA, Wersinga WM, Verbeek AM, Mourits MP, Koornneef L. A new ultrasonographic method to detect disease activity and predict response to immunosuppressive treatment in Graves' ophthalmopathy. Ophthalmology. 1993;199:556-61.

13. Char $\mathrm{DH}$, Norman D. The use computed tomography and ultrasonography in the evaluation of orbital masses. Surv Ophthalmol. 1982;27:49-63.

14. Byrne SF, Gendron EK, Glaser JS, Feuer W, Aha H. Diameter of normal extraocular in echography. Am J Ophthalmol. 1991;112:706-13.

15. Given-Wilson R, Pope RM, Mitchell MJ, Cannon R, McGregor A. The use of real-time orbital ultrasound in Graves' ophthalmopathy: a comparison with computed tomography. Br J Radiology. 1989;62:705-9.

16. Gerding MM, Prummel MF, Wiersinga WM. Assessment of disease activity in Graves' ophthalmopathy by orbital ultrasonography and clinical parameters. Clin Endocrinol. 2000;52:641-6.

17. Sabetti I, Toscano A, Specchia G, Balestrazz E. Alterations of the internal reflectivity of extra-ocular muscles associated with seve- ral clinical stages of Graves' ophthalmopathy. Ophthalmologica. 1998;212(suppl I):107-9.

18. Goodall $K L$, Jackson A, Leatherbarrow B, Whitehouse RW. Enlargement of the tensor intermuscularis muscle in Graves' ophthalmopathy. A computed tomographic and magnetic resonance imaging study. Arch Ophthalmol. 1995;113:1286-9.

19. Hosten N, Sander B, Cordes M, Schubert CJ, Schorner W, Felix R. Graves' ophthalmopathy: magnetic resonance imaging of the orbits. Radiology. 1989;172:759-62.

20. Polito $E$, Leccisotti A. Magnetic resonance imaging in Graves' orbitopathy: recognition of enlarged muscles and prediction of steroid response. Ophthalmologica. 1995;209:182-6.

21. Hoh HB, Laitt RD, Wakeley C, Kabala J, Goddard P. The STIR sequence magnetic resonance imaging in the assessment of extraocular muscles in thyroid eye disease. Eye. 1994;8:506-10.

22. Lennerstrand G, Tiam S, Isberg B, Landau Högbeck I, Bolzani R, Tallstedt $L$, et al. Magnetic resonance imaging and ultrasound measurements of extraocular muscles in thyroid-associated ophthalmopathy at different stages of the disease. Acta Ophthalmol Scand. 2007;85:192-201.

23. TaokaT, Iwasaki S, Uchida H, Fukusumi A, Kichikawa K, Nakagawa $H$, et al. Enhancement pattern of normal extraocular muscles in dynamic contrast-enhanced magnetic resonance imaging with fat suppression. Acta Radiologica. 2000;41:211-6.

24. Nagy VE, Toth J, Kaldi I, Damjanovich J, Mezosi E, Lenkey A, et al. Graves' ophthalmopathy: eye muscle involvement in patients with diplopia. Eur J Endocrinol. 2000;142:591-7.

25. Prummel MF, Wiersinga WM. Immunomodulatory treatment of Graves' ophthalmopathy. Thyroid. 1998;8:545-8.

26. Erickson BA, Harris G, Lewandowski MF, Murray KJ, Massaro BM. Echographic monitoring of response of extraocular muscles irradiation in Graves' ophthalmopathy. Int J Radiation Oncology. 1995;31:651-60.

27. Stamato FJC, Maciel RMB, Manso PG, Wolosker AMB, Paiva ER, Lopes $A C$, et al. Colchicine in the treatment of the inflammatory phase of Graves' ophthalmopathy: a prospective and randomized trial with prednisone. Arq Bras Oftalmol. 2006;69(6):811-6.

28. Troelstra A, Rijneveld WJ, Kooijman AC, Houtman WA. Correlation between magnetic resonance scans of extraocular muscles and clinical symptoms in Graves' ophthalmopathy. Doc Ophthalmol. 1988;70:243-9.

29. Utech $\mathrm{Cl}$, Khatibnia $\mathrm{U}$, Winter PF, Wulle KG. MR T2 relaxation time for the assessment of retrobulbar inflammation in Graves' ophthalmopathy. Thyroid. 1995;5:185-93.

30. Gerding MM, Van der Zant FM, Van Royen EA, Koornneef L, Krenning EP, Wiersinga WM, et al. Octreotide-scintigraphy is a disease activity parameter in Graves' ophthalmopathy. Clin Endocrinol. 1999;50:373-9.

31. Yanik B, Conkbayir I, Acaroglu G, Heckimoglou B. Graves' ophthalmopathy: comparison of the doppler sonography parameters with the clinical activity score. J Clin Ultrasound. 2005;33:375-80.

32. Delint PJ, Mouritis MPh, Kerlen CH, Scheenloop JJ, Wittebol-Post D. B-scan ultrasonography in Graves' orbitopathy. Doc Ophthalmol. 1993;85:1-4.

33. Fledelius HC, Zimmermann-Belsing T, Feldt-Rasmussen U. Ultrasonically measured horizontal eye muscle thickness in thyroid associated orbitopathy: cross-sectional and longitudinal aspects in a Danish series. Acta Ophthalmol Scand. 2003;81(2):143-50. 